Article

\title{
Innovation in an Existing Backpressure Turbine for Ensure Better Sustainability and Flexible Operation
}

\author{
Aleš Hromádka ${ }^{1,2, * \mathbb{E}}$, Martin Sirový ${ }^{1}$ and Zbyněk Martínek ${ }^{2}$ \\ 1 Regional Innovation Centre for Electrical Engineering, Faculty of Electrical Engineering, University of West \\ Bohemia, Univerzitní str. 2732/8, 30614 Pilsen, Czech Republic \\ 2 Department of Electric Power Engineering and Ecology, Faculty of Electrical Engineering, University of West \\ Bohemia, Univerzitní str. 2732/8, 30614 Pilsen, Czech Republic \\ * Correspondence: aleshrom@rice.zcu.cz; Tel.: +420-377-634-106
}

Received: 14 June 2019; Accepted: 5 July 2019; Published: 10 July 2019

check for updates

\begin{abstract}
Cogeneration power plants have already been operated in the Czech Republic for several decades. These cogeneration power plants have been mostly operated with original technologies. However, these original technologies have to be continuously innovated during the entire operation time. This paper is focused on one of the possible innovations, which could lead to better sustainability and improved flexibility of the cogeneration power plants. Backpressure turbines are still used in many cogeneration power plants. However, backpressure turbines are currently losing suitability for cogeneration power plants, because they always need sufficient heat demand for optimal operation. Backpressure turbines rapidly lose efficiency when facing a lack of heat demand, i.e., mostly in summer season. Currently, condensing turbines are a preferable option for cogeneration power plants, which generally achieve less effective operation, as condensing turbines are able to operate with optional heat demand. Therefore, backpressure turbines are often replaced by condensing turbines with regulated outputs. In spite of the current trend, this article will present an innovative topology, which retains the original backpressure turbine with the addition of the organic Rankine cycle for residual energy utilization.
\end{abstract}

Keywords: backpressure turbine; cogeneration power plant; organic Rankine cycle; cycle synthesis; innovative topology

\section{Introduction}

Cogeneration power plants (CPPs) offer excellent primary fuel utilization for electricity, heating and even cooling production. Most CPPs use brown coal, biomass or some combination of them as a fuel. Nowadays, the electric efficiency of CPPs is in $25 \%$ to $35 \%$ range according to turbine type, boilers, regenerative heaters, etc. The remaining energy can be used for heating, cooling or for technical purposes in households or industry plants. The total CPP efficiency can be around $90 \%$ when suitable conditions are met.

Most CPPs can change their electric production. Therefore, CPPs can mostly operate under partial electric production conditions to cover the daily load profile. This means that CPPs can participate in the support services for electrical networks. The support services are connected with higher prices for the electric production. It also means better economy for the CPPs.

The CPPs with backpressure turbines (BPTs) have problems under a lack of heat demand. The heat demand is very changeable during year. In winter season, there is no problem with a lack of heat demand, but the problem often occurs during the summer season. Therefore, CPPs with BPTs have to limit their production, especially during summer season. 
Moreover, there always is the certain requirement for electric production by CPPs from the electrical network, which must be met. The requirement very rarely matches with the optimal CPP operation conditions. The variable operation of CPPs is always connected with a drop in their efficiency.

If the heat demand will not sufficient, CPPs with BPTs cannot reach their optimal efficiency. For these reasons, the on average efficiency of the CPPs drops to $50 \%$.

Among the problems of currently operated CPPs with BPTs the following may be highlighted:

- $\quad$ Limited options of heating energy storage.

- A problem with assuring enough heat demand, especially during summer season.

- Bad electric production flexibility for economical operation of the CPPs during the year.

- The more significant drop of electric production flexibility during the summer season.

\section{Definition of the BPT Problem and its Current Solution}

In other words, the main problem of CPPs with BPTs are operation limitations when facing a lack of heat demand. A key question is how can these operating limitations be solved? This paper will be further focused only on one CPP located in Pilsen. Firstly, it is necessary to mention how these limitations can be solved in the current CPP without some innovative implementations. The technological steam production in the CPP is considered as the same during the whole year. Certain part of heat energy is needed during the whole year for heating tap water for households.

The first utilization of heat energy when facing a lack of heat demand can be by absorption chillers, which have been placed in several buildings in Pilsen. Seven absorption chillers have already been installed in Pilsen with a total chilling power 6732 MWch. Lithium bromide is used in the chillers as the absorption medium. However, the chillers' utilization is strongly dependent on the ambient temperature. In addition, the chilling power of the chillers can be sometimes limited by a lack of chill demand. Currently, the already installed chillers have only a small impact on solving the problem due to their low chilling power.

Two other options to deal with a lack of heat demand are sufficient for solving of this problem. However, these two option are based on total thermal energy loss at the end of the BPT.

The first of the options has been using a mechanical dry condenser (DMC), which has been in operation in the investigated CPP. The DMC only allows the emission of thermal energy to the atmosphere.

The second of the options has been that the steam at end of the BPT flows out directly from the cycle. This option causes both thermal energy losses and the loss of demineralized water. These last two options therefore do not seem to be suitable for ensuring the CPP sustainability. Therefore, there is a place for improvement of the current situation in the CPP.

One of the possible solutions how to improve the situation could be realized by increasing the installed chilling power in Pilsen. However, it is necessary to ensure sufficient chilling demand to justify the initial investment in the needed absorption chillers.

Secondly, there are several options to improve the current situation by some innovative ways. In other words, a certain amount of heat utilization can be covered by some innovative mechanisms when facing a lack of heat demand. A convenient optional way to deal with a lack of heat demand would appear using some form of thermal energy storage (TES) for the residual heat at the output of the BPT. TES is able to store excess thermal energy and use it hours, days, or months later. There are several such technologies. Most TES are based on the Phase Change Material (PCM) principle [1]. Theoretically, three types of the PCM could be used [1]:

- $\quad$ salt hydrates with a $7-117^{\circ} \mathrm{C}$ range of utilization,

- organic materials with a $1-167^{\circ} \mathrm{C}$ range of utilization,

- $\quad$ solid-solid materials with a $40-180^{\circ} \mathrm{C}$ range of utilization.

There are several technical requirements, which should be take into account in the design of TES such as [1]: 
- total thermal capacity,

- size, shape and volume,

- thermal losses,

- efficiency of charging and discharging.

The optimal design of TES strongly depends on the maximum size of the storable thermal energy. The size is tightly connected with investment costs [2].

There are some pros of TES [1]:

- storage possibility of a huge amount of thermal energy (80-500 Wh/L, 80-250 Wh/kg),

- no negative impact on the environment,

- low thermal losses (0.05-1\% per day),

- low investment cost (3-60 USD/kWh),

- lifetime about 10-30 years.

However, it is necessary to mention some cons of TES as well [1]:

- the low thermal efficiency TES (30-60\%),

- bad dynamic properties of TES (the response time can be from several minutes to hours).

There are several opportunities for utilizing TES technology in current CPPs. However, that TES application has to be huge (i.e., several GWh) to accommodate all the residual energy produced by the BPT. Another option to deal with a lack of heat demand can be the utilization of the residual heat for different biomass conversion processes.

Part of the residual heat from the combustion process in the Pilsen CPP is currently used for drying of imported biomass. There are several thermochemical biomass conversions, which can consume the residual heat such as [3]:

- burning and co-burning of biomass (already used)—electricity, heat, steam,

- distillation-coal, gas, tar,

- pyrolysis-gas, liquid, coal,

- gasification-coal, gas, tar,

- hydro-gasification-liquid fuels.

However, all of these thermochemical processes except the burning require much higher residual energy parameters than can be provided by the BPT. The other reason why these thermochemical processes are not suitable for that utilization because of a lack of nearby biomass. Around 100,000 tons of biomass are burned in the Pilsen CPP. Most of that biomass must be imported from a radius of 100 kilometers around the city.

Most of the already mentioned possibilities could partly solve the lack of heat demand problem of the BPT, but none of them is able to solve the problem completely. The identified problem could be solved by an implementation of an organic Rankine cycle (ORC) in the current BPT. That is the reason why this paper will be mainly focused on that type of innovation.

\section{Description of the Investigated Cogeneration Power Plant in Pilsen}

\subsection{History of the Cogeneration Power Plant in Pilsen}

The first CPP was built at the same place as the current CPP in 1985. This first CPP was composed of two identical supercritical solid fuel fired boilers (B4 and B5) with a total thermal power $256 \mathrm{MWt}$ and the original BPT (TG1) with a nominal electrical power of 55 MWe. The installed boilers worked simultaneously. This means that both of them produced overheated steam for the BPT. The BPT had two main functions in the original CPP: 
- The thermal power has been transformed from steam into mechanical power on the shaft, which was connected with an electric generator.

- The thermodynamic parameters of the steam at the end of the BPT have been reduced to $105^{\circ} \mathrm{C}$, 1.2 bar. These parameters were suitable for the basic heating demand in a district heating system.

Thus the BPT did not have a classical condenser. Instead of a condenser, the BPT had a basic heater for district heating.

In the case of a lack of thermal energy at the end of the BPT for enough heating demand, it has been possible to supply superheated steam to peak heaters, which balanced between supply and demand, especially during winter season. However, the usage of the peak heaters is connected with a partial loss of the steam for the BPT.

In 1999, the second stage of the power plant was built. This stage included the implementation of a condensing turbine (CT) with a nominal electrical power $67 \mathrm{MWe}$ (maximal $70 \mathrm{MWe}$ ) and the building of a fluidized bed combustion boiler, which has been interconnected with the already built boilers with a heating power of $128 \mathrm{MWt}$. At the same time, the BPT has been overhauled and its electrical power increased up to 70 MWe.

In 2010, the latest technology recovery was added. That has been connected to the implementation of another CT with a nominal electrical power of 10.3 MWe (maximal power 13.5 MWe) and building another fluidized bed combustion boiler, which has only burned biomass with a heating power of 38.5 MWt ever since.

\subsection{Current Technology State in Cogeneration Power Plant in Pilsen}

Actual technological flowsheet of cogeneration power plant in Pilsen is shown in Figure 1. Currently, all three building stages are operated simultaneously in the power plant. There is the main steam collector, which supplies steam to the BPT and to the bigger CT. The steam from the collector is created by the three boilers from the first and second building stages of the power plant. In case of higher heating requirements for superheated steam from the main collector it can be led to the PRs, where the energy from superheated steam is transferred for heating water. There are three peak heaters, which can be used simultaneously during extreme heat demand periods. However, it is necessary to mention that the usage of the superheated steam in peak heaters significantly decreased the electricity production options in the power plant. The parameters of the main collector or the input parameters of both already mentioned turbines are $13.35 \mathrm{MPa}$ and $540{ }^{\circ} \mathrm{C}$.

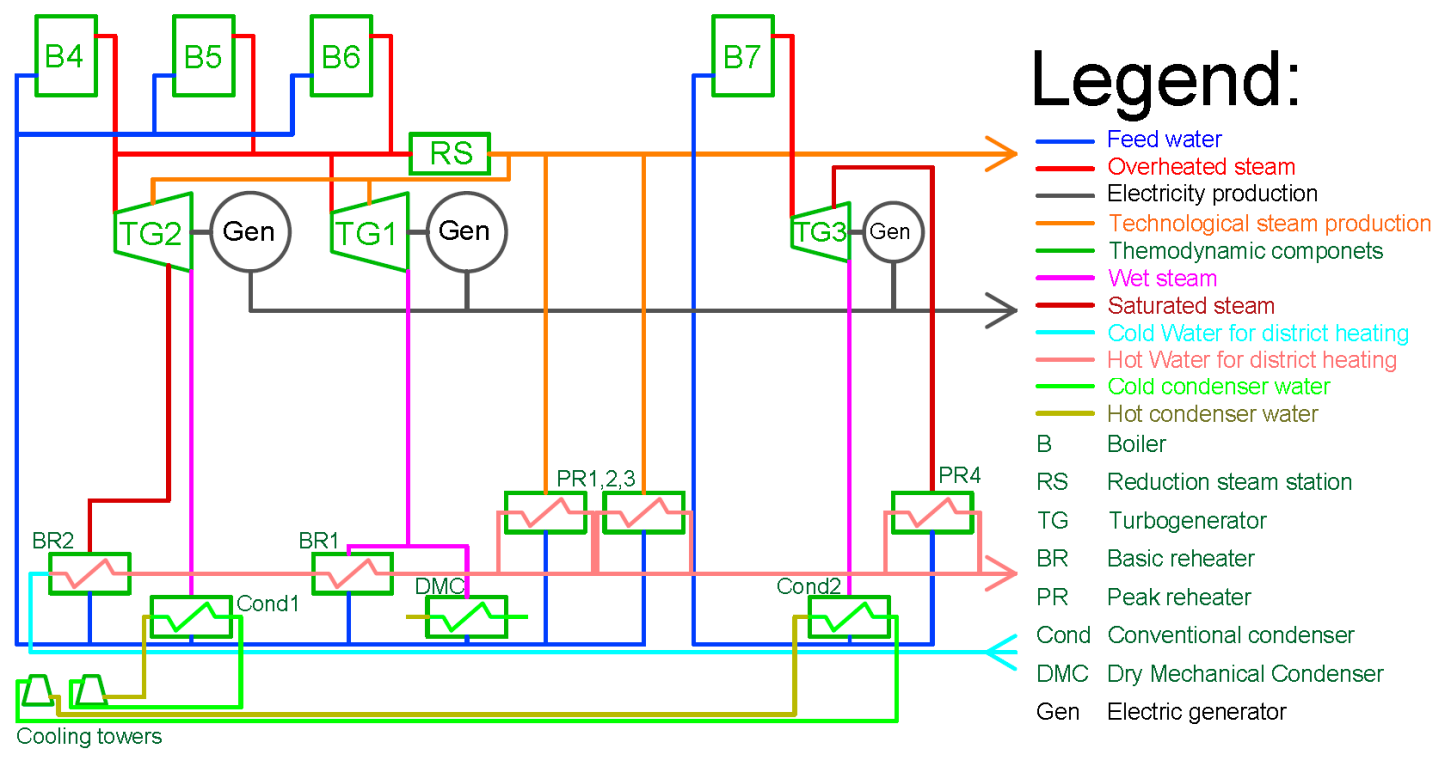

Figure 1. Actual technological flowsheet of cogeneration power plant in Pilsen [4]. 
The BPT in the CPP has two pressure stages, four non-regulated outlets to regenerative heaters and one regulated outlet at the end of the first stage of the turbine for the technological needs for usage of steam. Suitable parameters for BR of district heating are found at the end of the BPT. These suitable parameters are around $0.12 \mathrm{MPa}$ and $104.8^{\circ} \mathrm{C}$. In the case of higher electricity production requirements, the DMC can be connected to the outlet of the BPT. The DMC can be described as a ventilator assembly, which creates conditions for transfer of the residual energy from the steam behind the turbine to ambient air. However, this option is connected with huge loses of energy from the combustion process as well as a significant decrease of the whole efficiency. On the other hand, this operation is occasionally used for the temporary increase of electrical power during higher energy price periods according to the daily load diagram.

The bigger CT has also two pressure stages, two non-regulated outlets to regenerative heaters and two regulated outlets for heating needs. The first regulated outlet can also provide s certain amount of steam for technological usage or the steam can be used for regenerative heating in the deaerator. The second regulated outlet can provide steam to the basic heater. However, the second outlet can be also used in pure condensing operation for regenerative heating. CTs always contain a condenser for condensing wet steam onto water at the end of the turbine. The emission parameters of the turbine are required to be as low as possible for maximal utilization of the exergy. However, this requirement is strongly dependent on ambient temperature and it is difficult to influence it.

The third building stage has been built separately from the previous ones. The main difference from the other building stages has already been mentioned, it uses biomass as a fuel for the boiler. This building stage contains the smaller CT. The smaller CT has just one pressure stage, one regulated outlet and two non-regulated outlets to regenerative heaters. The input pressure and temperature of the smaller turbine are $6.7 \mathrm{MPa}$ and $490^{\circ} \mathrm{C}$. The turbine has also an option to operate in cogeneration mode. However, the subsidies policy is unfairly established, as it offers the possible subsidy only during pure condensing operation. Therefore, this unit is mainly operated in pure condensing operation, in another words only electricity production. However, the regulated outlet of the turbine can used for the peak heater. It means that in case of extreme heat demand the cycle can cover it.

\subsection{Differences between Backpressure Turbines and Condensing Turbines}

The behavior of both already mentioned turbines during the various electric and heat production scenarios will be shown in following figures.

Firstly, the typical trend of BPTs is shown in Figure 2, i.e., the increase of the electric production is tightly connected with the increase of the heat production. Obviously, there is a dependence between electric and heat production. However, the dependence causes a problem when there is no or low heat demand. The heat demand is not usually sufficient during the summer season. In addition, a problem occurs with condensing of the whole water volume behind the BPTs, which requires some additional cooling technologies, e.g., DMC, etc. [5].

Although, BPTs' main advantage is higher cogeneration efficiency than CTs under optimal conditions. However, the optimal conditions are met only during the winter season, which is shown in Figure 3. Therefore, the operation of the BPTs must be limited, especially in the summer season. If the BPTs will operate at unoptimal conditions, the cycle efficiency loss is very significant and that is a crucial problem [5].

Area 1 in Figure 3 cannot be covered by the BPT. The BPT generates around $25 \mathrm{MWe}$ and $54 \mathrm{MWt}$ at $40 \%$ load, which is the minimal suitable load for the BPT. A lower load than the minimal suitable load is possible, but it results in significant cycle efficiency losses. Area 2 can be covered by the BPT without any other heat sources. The BPT can produce $70 \mathrm{MWe}$ and almost $138 \mathrm{MWt}$ at $100 \%$ load. Area 3 can be covered by the BPT, but other heat sources must also used to cover the total heat demand.

However, Figure 4 shows that the problem, which is typical for the BPT, does not exist for the CT. The CT offers more flexible operation than the BPT, which is represented by the variable area. The CT is not limited by a lack of heat demand and can be operated under pure condensing operation conditions. 
Better flexibility in production is the reason why CTs are currently a more preferable choice than BPTs, which is obvious in Figure 4 compared with Figure 2 [5].

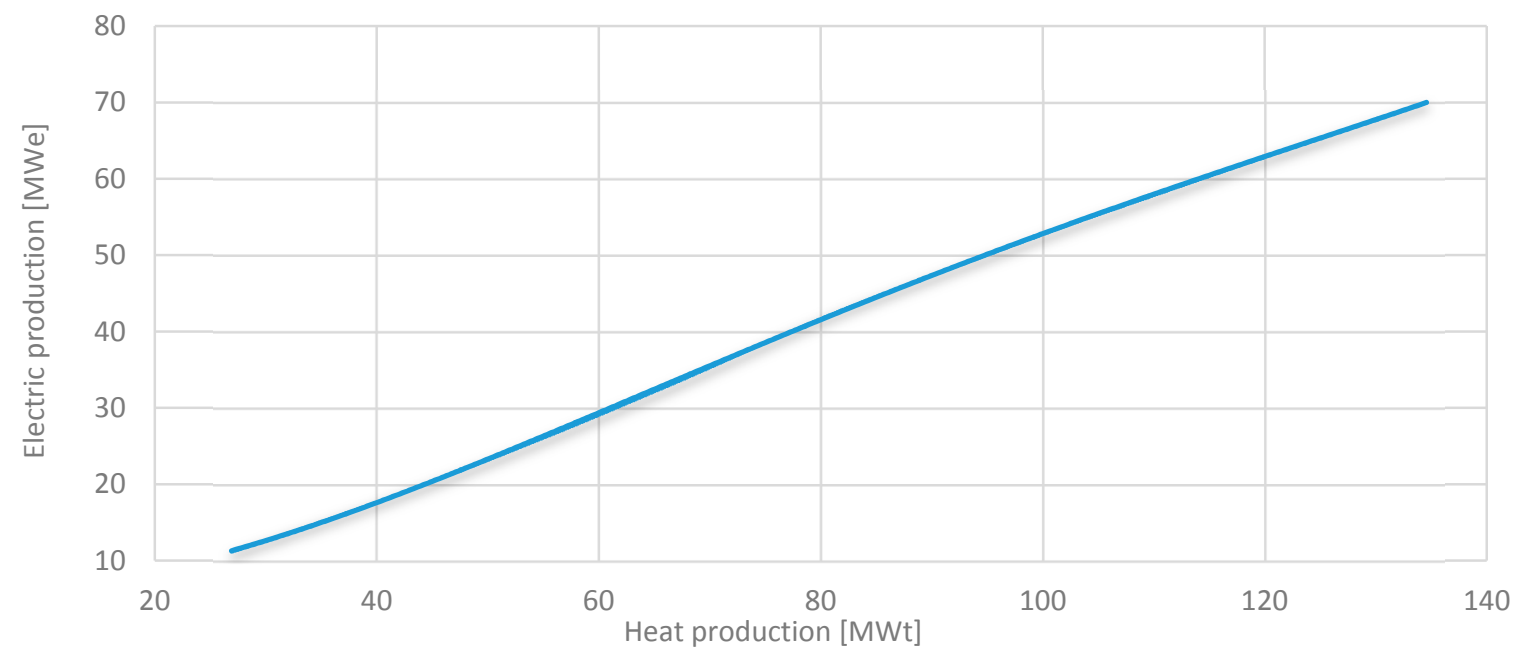

Figure 2. Production trend for electric and heat production of the BPT in the Pilsen CPP [5].

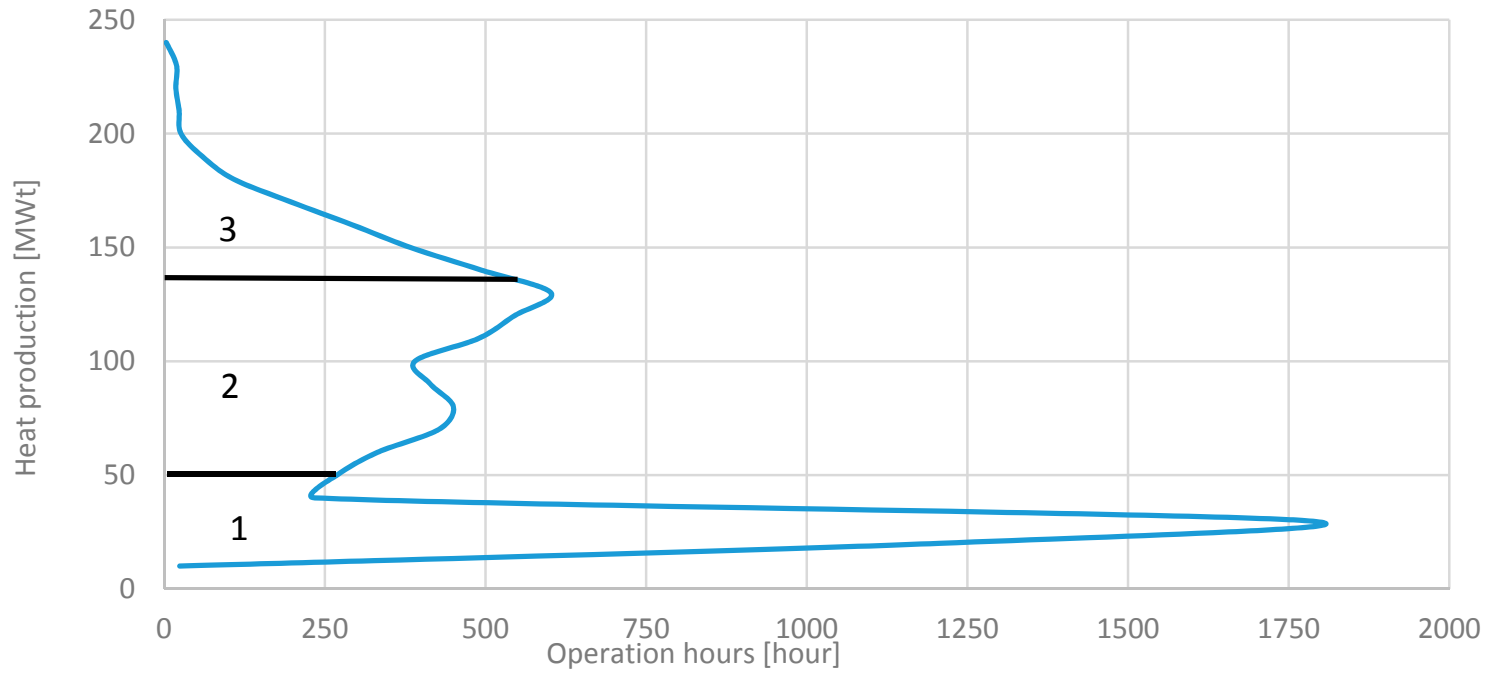

Figure 3. Limitation of the BPT at the produced heat power by the CPP in 2016 [5].

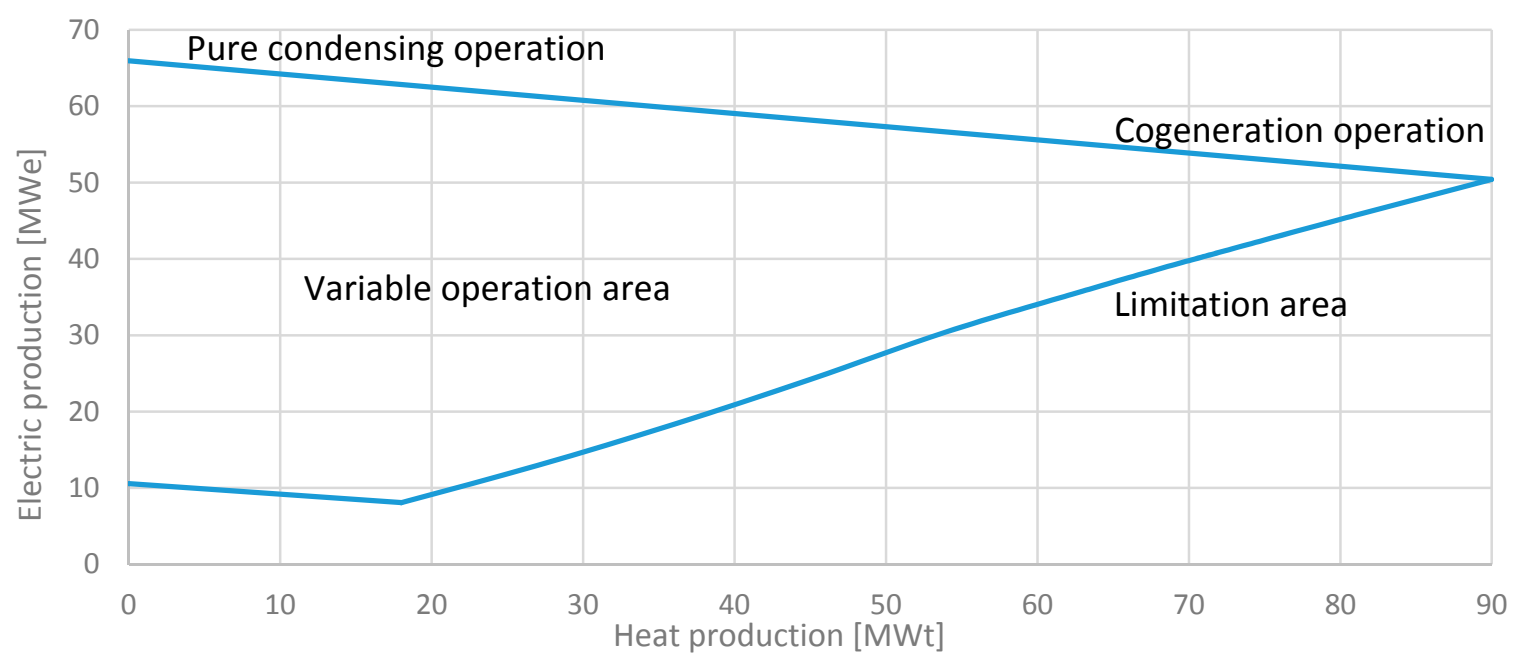

Figure 4. Dependence between electrical and heat production for the bigger CT in the CPP [5]. 
The CT can cover area 1 in Figure 5 without any other heat sources. The CT can produce 50 MWe and almost $90 \mathrm{MWt}$ at $100 \%$ in full cogeneration operation. The second limiting state is the pure condensing operation with electric power 69 MWe and without heat production. Heat production can be flexible to meet various heat demands. The CT has no lower limit for the heat production. Area 2 can be covered by the $\mathrm{CT}$, but other heat sources are needed.

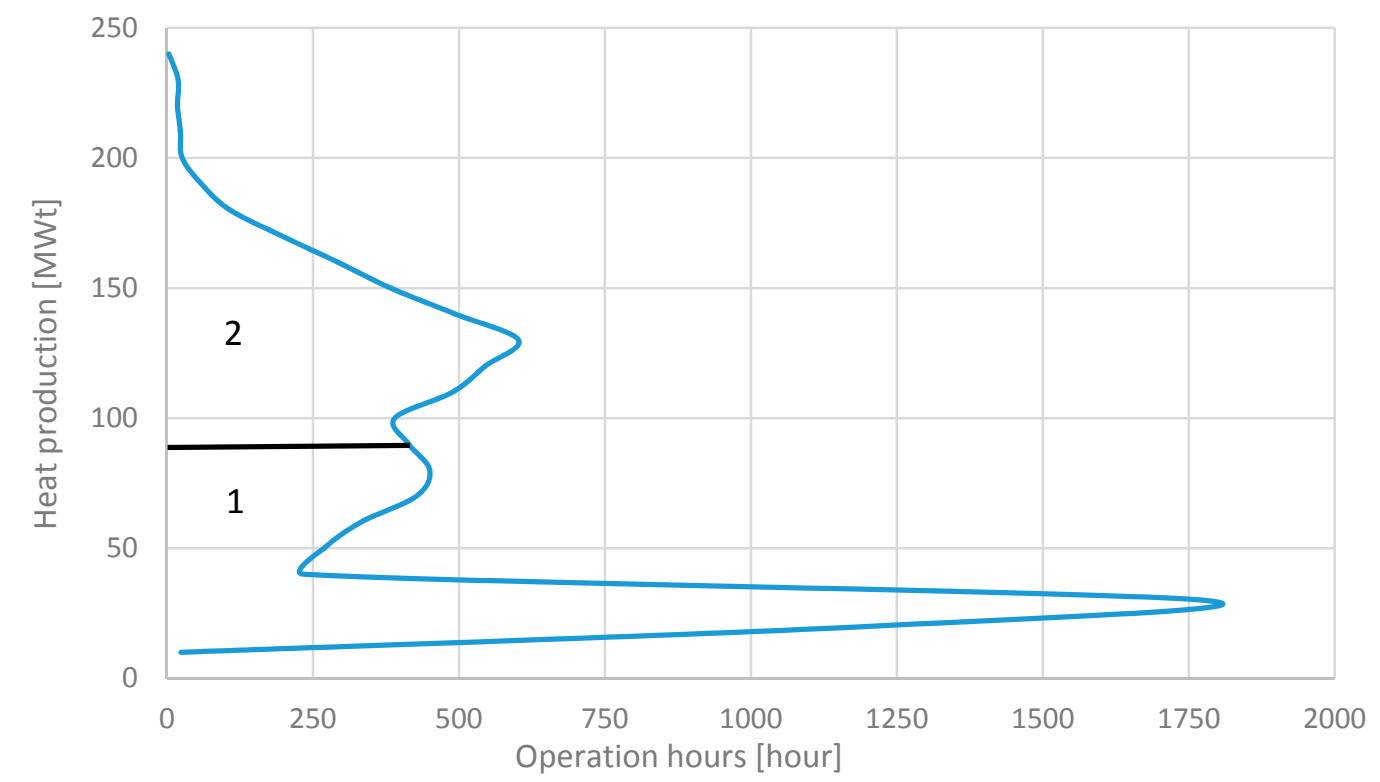

Figure 5. Limitation of the bigger CT at the produced heat power by the CPP in 2016 [5].

\section{Description of ORCs}

\subsection{Important Information about ORCs}

ORCs have a similar concept as classic thermal cycles (CTCs). The main difference is that heat transfer is realized by an organic compound with a lower boiling temperature compared with water in CTCs. The suitable heat sources for ORCs have temperatures from 80 to $300{ }^{\circ} \mathrm{C}[6,7]$. It is good to summarize here the pros and cons of ORCs. Firstly, the pros of ORCs will be mentioned [6-9]:

- Usage of heat sources with lower temperatures than for CTCs.

- High efficiency of the cycle and isoentropic turbine efficiency up to $90 \%$.

- Minimal mechanical stress, i.e., less mechanical requirements for the materials in ORCs.

- Simple design of the turbine (only one stage).

- Absence of moisture during vapor expansion in the ORC turbine.

- Easy start-stop, automatic, continuous and quiet operation.

- No need to demineralize water.

- Long lifetime with high availability, i.e., up to $50,000 \mathrm{~h}$ with availability up to $98 \%$.

- Variable operation from 20 to $100 \%$ of the load with low drop of the cycle efficiency.

- Minimal observation and measurement requirements just about 3-5 h per week.

Secondly, the cons will be mentioned $[6,9,10]$ :

- Some of the organic compounds used for ORCs could be toxic, flammable or harmful.

- Degradation of a medium in ORCs at LTO is connected with worse thermodynamic properties.

- The price of organic compounds is higher than for demineralized water.

- Sources with lower energy needs higher mass flow than CTCs and higher feed pump power.

- ORCs must be hermetically sealed due to the negative features of some organic compounds. 
The topology of ORCs is very dependent on the selection of the working medium for the ORCs. There are two basic types of ORCs:

- Subcritical.

- Transcritical.

A subcritical cycle has been chosen for further investigation, because of its convenience for the defined heat source. Subcritical cycles operate with thermodynamic parameters under the critical curve of a working medium. The thermodynamics of the subcritical cycle with a typical R-600a working medium is shown in the T-s diagram in Figure 6.

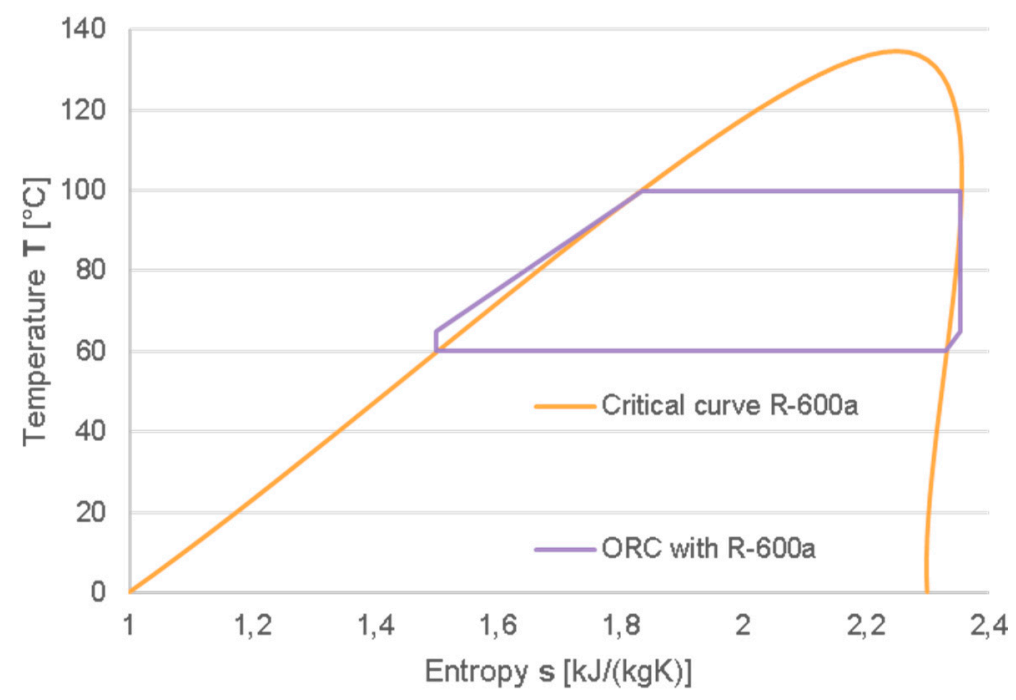

Figure 6. T-s diagram of isobutane (R-600a) used in a subcritical ORC as working medium [6,8].

The topology of the subcritical cycle is shown in Figure 7. The improvement of the cycle efficiency can be achieved by a heat regenerator, which is placed at the output of the ORC turbine.

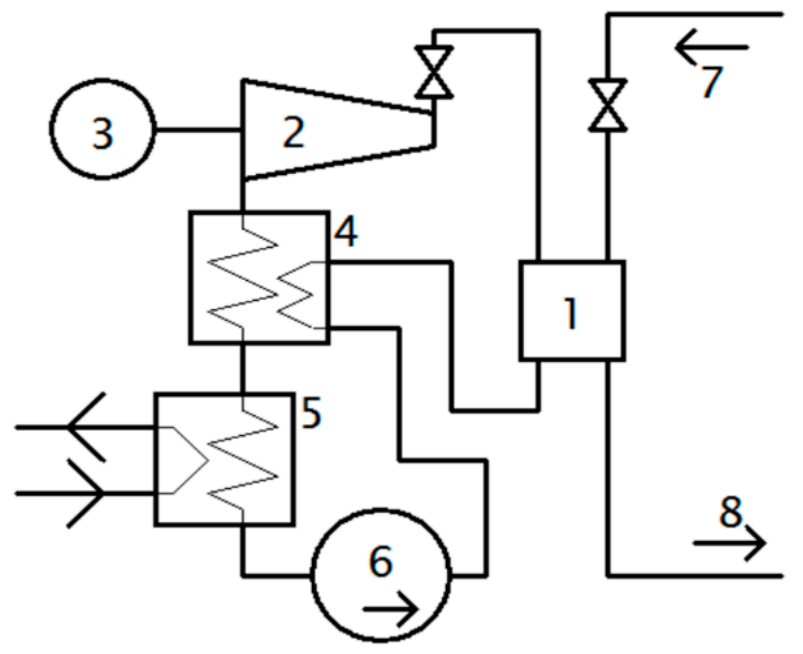

Figure 7. ORC topology with subcritical critical curve $[6,8]$.

Component 1 in Figure 7 represents an evaporator. Component 2 represents an ORC turbine. Component 3 represents a generator. Component 4 represents a heat regenerator. Component 5 represents a condenser. Component 6 represents a feed pump. Component 7 represents input of heat source. Component 8 represents the heat source output. 


\subsection{Working Media for the ORCs}

Suitable choice of the working medium determines many properties of the ORC such as:

- thermodynamic efficiency,

- lifetime,

- level of sealing needed,

- level of maintenance,

- level of danger (in the case of loss of the medium).

Firstly, the heat source is determined and all necessary thermodynamic parameters of the heat source are calculated. Secondly, working media are investigated according to their convenience for the given heat source. Each of the media has its own critical curve, which determines the thermodynamics for the medium.

Selection of a medium with higher vapor density is possible because these media have lower condensing pressures. On the other hand, media with lower vapor density require a larger condenser for condensation and this is connected with additional costs.

The ORC efficiency can be increased by using a higher pressure of the working medium at the input of the ORC turbine (OT). However, this is connected with higher investment costs. In the case of higher pressure utilization, the cycle must be made more robust and its feed pump needs to create a higher pressure difference. This means a higher power of the feed pump and of course additional costs. Investigation of optimal operating conditions should be performed before realization of a cycle.

Some working media can degrade at higher temperatures than the nominal temperature or during long-time operation. Therefore, it is often convenient to ensure stable thermodynamic conditions such as heat source temperature. The maximum heat source temperature must be limited by the chemical properties of the working medium.

According to $[6,10]$, the crucial properties for choosing a working medium are:

- impact on the environment,

- flammability (in air at $60^{\circ} \mathrm{C}$ and $101.325 \mathrm{kPa}$ ),

- toxicity (in air at $60^{\circ} \mathrm{C}$ and $101.325 \mathrm{kPa}$ ),

- ozone depletion potential (ODP),

- global warming potential (GWP),

- Refrigerant concentration limit/immediately danger to life or health (RCL/IDLH, in g/m³).

\section{Design of the Innovative Technology}

\subsection{Introduction of the Innovative Idea}

The ORC concept has been known since the 1950s and are currently many ORCs are utilized for electric power production. The current ORCs can be used in heat recovery from lower temperature sources such as biomass combustion, industrial waste heat and geothermal heat [6].

All the current ORC applications assume separated operation [6-10]. The brand new concept of the ORC application is the straight implementation of the ORC into the original BPT cycle. It means that a synthesis of both cycles will be used, which will solve the problems of the original BPT. In other words, low interest in BPTs could be improved by this innovation in the future.

In winter season, this innovation does not have such an effect, because the BPT is mainly operated in cogeneration mode. However, this innovation allows the original topology to become more flexible especially during the summer season, when there is a lack of heat demand.

In case of a lack of heat demand, the residual energy from the BPT will be used for additional electricity production. The implementation of the ORC will allow condensing the wet steam at the output to water and will utilize residual energy for evaporation of the secondary medium, which will feed the OT. 
Currently, one BPT cycle operated in the investigated CPP. The BPT topology is shown in Figure 8. Regenerative heating in the cycle has been neglected, because is irrelevant for the assumed innovation.

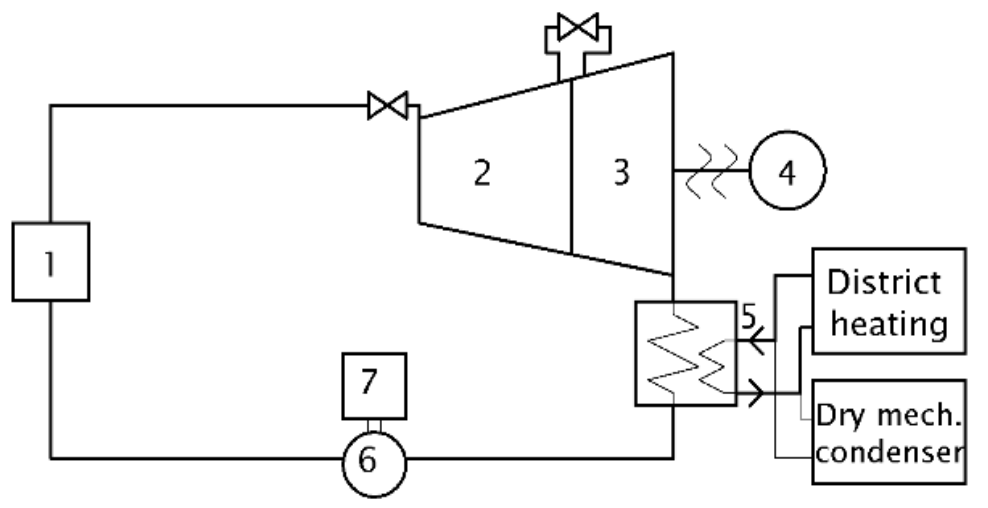

Figure 8. Basic topology of the BPT cycle in the Pilsen CPP [5].

Component 1 in Figure 8 is a boiler. Component 2 represents a HP part of a BPT. Component 3 represents a LP part of a BPT. Component 4 represents a generator. Component 5 represents a heat exchanger. Component 6 represents a feed pump. Component 7 represents a frequency converter.

The original topology has two options to liquefy wet steam at the output of the LP BPT part to water:

- By a basic heater for district heating (with heat demand).

- By a dry mechanical condenser (with no heat demand).

District heating can be used in the case of heat demand. The cogeneration efficiency of this operation has been in range from $70 \%$ to $90 \%$. Electric production efficiency has mostly been around $30 \%$ and the heat production efficiency has reached up to $60 \%$. However, the cogeneration efficiency depends on several operation factors. The DMC offers an option of using the BPT for pure electricity production. The efficiency has never been higher than the electric production efficiency (i.e., $30 \%$ ). This operation is used in the case of necessity to cover the daily load diagram during the summer season. It is connected with a higher price of electric power. Therefore, the less effective operation can be economically convenient for the CPP.

\subsection{Principle of the Innovation Topology}

The new innovative topology, which is shown in Figure 9, is called a synthesis of the original BPT cycle with the ORC. Component 1 in Figure 9 represents a boiler. Component 2 represents a HP part of the BPT. Component 3 represents a LP part of the BPT. Component 4 represents a generator. Component 5 represents a heat exchanger. Component 6 represents an ORC evaporator. Component 7 represents an OT. Component 8 represents a generator. Component 9 represents a recuperative heater. Component 10 represents a condenser. Component 11 represents a feed pump for ORC. Component 12 represents a feed pump for original cycle. Component 13 represents frequency converter.

An additional pipeline at the output of the BPT and two valves for setting the mass flow rate between the ORC evaporator and heat exchanger for the district heating must be added to the original cycle. The thermodynamic parameters of wet steam at the output from the original turbine (i.e., $0.12 \mathrm{MPa}$ and $104.8^{\circ} \mathrm{C}$ ) will be used for vaporization of a working medium in the ORC evaporator. Energy transferred from the original cycle to the additional ORC will evaporate a working medium and at the same time will liquefy wet steam to water in the original cycle. Vaporized working medium will be led to the OT, where the energy from the medium will be transformed into mechanical work by rotating rotor blades. Of course, the rotor of the OT will be connected with the generator. The residual energy at the output of the OT after expansion will be led to a recuperative heater, where the liquid medium can be preheated before the evaporator for increasing the ORC efficiency. After that, the medium will 
be led to a condenser for the ORC, where the steam medium will be liquefied. Liquefied medium will be led to a feed pump for the ORC, where the medium pressure will be increased. Finally, the medium will again continue to ORC evaporator. Several benefits will be offered by the innovative topology:

- Increasing the electric production for better coverage of the daily load diagram.

- Possibility of higher flexibility of electric and heat production than the original BPT topology.

- Utilization of residual energy from the original BPT cycle at time of a lack of heat demand.

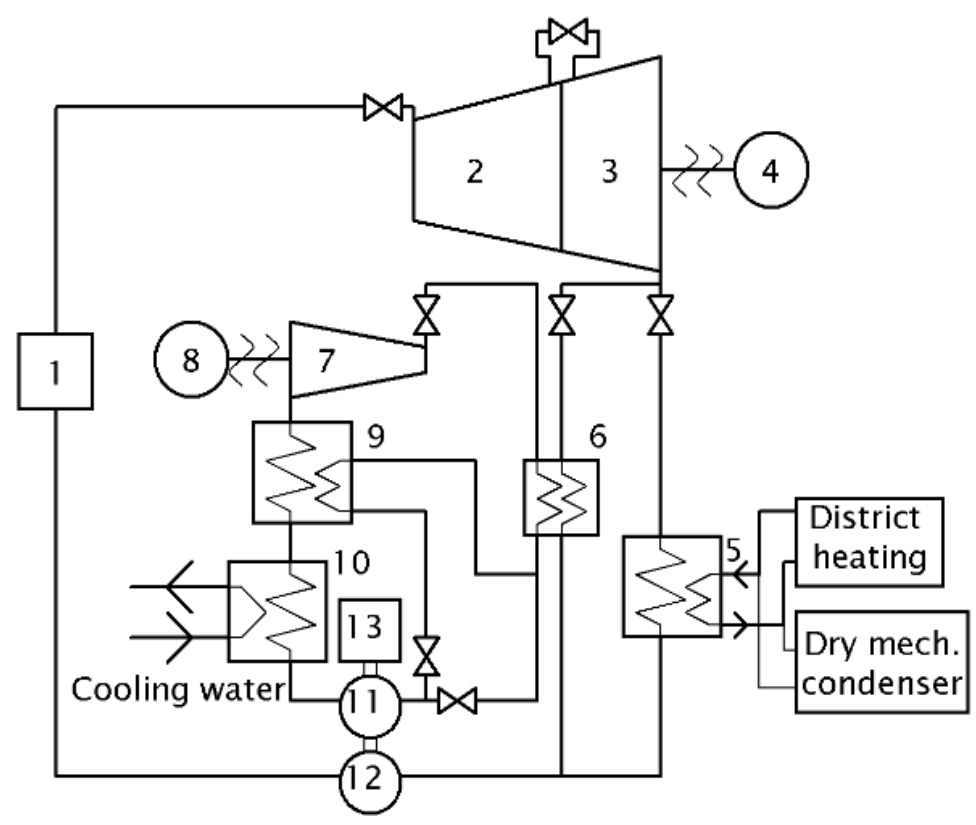

Figure 9. Assumed innovative topology with implementation of the ORC to the original BPT cycle.

\subsection{Choosing of Working Medium for Models}

Although, several working media can be used for this type of application. For simplification, just one suitable medium will be chosen. Isobutane (R-600a) has been chosen as the working medium. The critical parameters of R-600a are $134,9^{\circ} \mathrm{C}$ and $3695 \mathrm{MPa}$. The ORC with R-600a is operated as a subcritical ORC. Models in other references have worked with this medium $[6,10]$. The reasons why R-600a has been chosen, are:

- chemical durability,

- no impact on the environment,

- no toxicity in air at $60^{\circ} \mathrm{C}$ and $101.325 \mathrm{kPa}$,

- $\quad$ no ozone depletion potential (ODP),

- no global warming potential (GWP),

- no danger to life or health.

One small disadvantage of R-600a is its flammability in air with parameters of $60^{\circ} \mathrm{C}$ and $101.325 \mathrm{kPa}$. However, the places where it is assumed that R-600a will be present can be hermetically sealed.

\subsection{Basics of Modeling}

This section describes one possible way to realize implementation of the ORC in the BPT cycle.

The Dymola software has been used for all thermodynamic models. All the models have been simulated for the nominal thermodynamic parameters of the original cycle (i.e., $70 \mathrm{MWe}$ ). The models have described the nominal operation under lack of heat demand conditions. The thermal energy from 
the LP part of the BPT has been led to the ORC evaporator. This means the total energy from the BPT has been used for additional electric power in the ORC.

Firstly, it is necessary to determine a mass flow rate of R-600a, which is sufficient for condensing the total amount of wet steam at the output from BPT. Therefore the model shown in Figure 10 has been developed. The model consists of steam turbine stages and a heat exchanger. Each of turbine stages represent one part of the BPT with the same mass flow rate. The steam turbine model is based on Stodola's cone law (law of the ellipse) with an optional efficiency degradation using Baumann's formula. Main equation for the model of Stodola's turbine is as follows [11,12]:

$$
\frac{m \sqrt{T_{01}}}{p_{0 I}}=k \sqrt{\left[1-\left(\frac{p_{02}}{p_{01}}\right)^{2}\right]} .
$$

where symbol $m$ represents mass flow rate. Symbol $T_{01}$ represents inlet temperature. The term $p_{02} / p_{01}$ represents a ratio between input and output pressure. Constant $k$ represents a typical constant for Stodola's equation, which is given by the type of turbine.

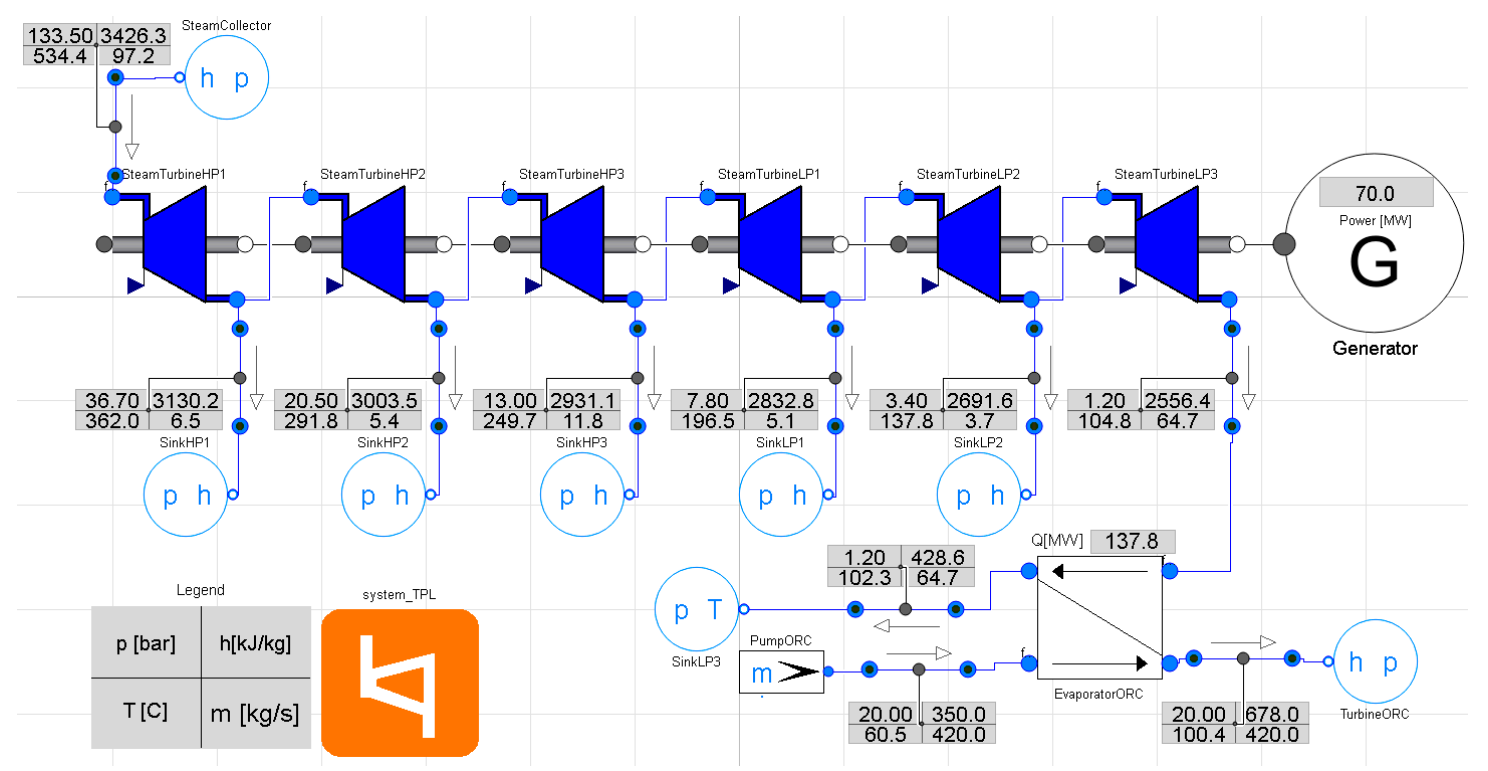

Figure 10. The original BPT with the ORC evaporator at the nominal operation.

Most partial outputs are used for regenerative heaters. The output from the last turbine stage will be used for evaporation of the R-600a in the evaporator. The evaporator has been modeled as a static heat exchanger using the logarithmic mean temperature difference (LMTD). The main equation for the model of a static heat exchanger is [11]:

$$
Q=k_{c} * A_{\text {heat }} * \frac{d T_{2}-d T_{1}}{\ln \left|d T_{2}\right|-\ln \left|d T_{1}\right|} .
$$

where $Q$ represents the transferred heat power. $k_{c}$ represents heat transfer coefficient. $A_{\text {heat }}$ represents transfer area. $d T_{1}$ and $d T_{2}$ represent temperature differences between primary and secondary side.

Feed pump models use a quadratic flow characteristic. It describes a centrifugal pump. The hydraulic characteristic (head vs. flow rate) is represented, as well as the pump power consumption.

\subsection{Identification of Thermodynamic Parameters for the Modeling}

The model parameters have been chosen at the nominal BPT operation. These thermodynamic parameters are shown in Table 1. The thermal power source for the BPT has been modeled as the main steam collector (MSC). 
Table 1. Nominal parameters for modeling of the innovative topology.

\begin{tabular}{|c|c|c|}
\hline Thermodynamic Parameters & Value & Unit \\
\hline Pressure in the main steam collector & 133.5 & bar \\
\hline Temperature in the main steam collector & 535 & ${ }^{\circ} \mathrm{C}$ \\
\hline Enthalpy in the main steam collector & 3426.3 & $\mathrm{~kJ} / \mathrm{kg}$ \\
\hline Mass flow rate in the main steam collector & 97.2 & $\mathrm{~kg} / \mathrm{s}$ \\
\hline Pressure at the first arc of the HP turbine stage & 36.7 & bar \\
\hline Temperature at the first arc of the HP turbine stage & 361.5 & ${ }^{\circ} \mathrm{C}$ \\
\hline Enthalpy at the first arc of the HP turbine stage & 3130.5 & $\mathrm{~kJ} / \mathrm{kg}$ \\
\hline Mass flow rate at the first arc of the HP turbine stage & 6.5 & $\mathrm{~kg} / \mathrm{s}$ \\
\hline Pressure at the second arc of the HP turbine stage & 20.5 & bar \\
\hline Temperature at the second arc of the HP turbine stage & 291.6 & ${ }^{\circ} \mathrm{C}$ \\
\hline Enthalpy at the second arc of the HP turbine stage & 3003.8 & $\mathrm{~kJ} / \mathrm{kg}$ \\
\hline Mass flow rate at the second arc of the HP turbine stage & 5.4 & $\mathrm{~kg} / \mathrm{s}$ \\
\hline Pressure at the End of the HP Turbine Stage & 13 & bar \\
\hline Temperature at the end of the HP turbine stage & 249.6 & ${ }^{\circ} \mathrm{C}$ \\
\hline Enthalpy at the end of the HP turbine stage & 2930.5 & $\mathrm{~kJ} / \mathrm{kg}$ \\
\hline Mass flow rate at the end of the HP turbine stage & 11.25 & $\mathrm{~kg} / \mathrm{s}$ \\
\hline The mass flow rate the technological steam & 9.7 & $\mathrm{~kg} / \mathrm{s}$ \\
\hline Mass flow rate at the input of the LP turbine stage & 73.5 & $\mathrm{~kg} / \mathrm{s}$ \\
\hline Pressure at the fourth arc of the LP turbine stage & 7.8 & bar \\
\hline Temperature at the fourth arc of the LP turbine stage & 196.8 & ${ }^{\circ} \mathrm{C}$ \\
\hline Enthalpy at the fourth arc of the LP turbine stage & 2832.2 & $\mathrm{~kJ} / \mathrm{kg}$ \\
\hline Mass flow rate at the fourth arc of the LP turbine stage & 5.1 & $\mathrm{~kg} / \mathrm{s}$ \\
\hline Pressure at the fifth arc of the LP turbine stage & 3.4 & bar \\
\hline Temperature at the fifth arc of the LP turbine stage & 137.9 & ${ }^{\circ} \mathrm{C}$ \\
\hline Enthalpy at the fifth arc of the LP turbine stage & 2690.9 & $\mathrm{~kJ} / \mathrm{kg}$ \\
\hline Mass flow rate at the fifth arc of the LP turbine stage & 3.75 & $\mathrm{~kg} / \mathrm{s}$ \\
\hline Pressure at the end of the LP turbine stage & 1.2 & bar \\
\hline Temperature at the end of the LP turbine stage & 104.8 & ${ }^{\circ} \mathrm{C}$ \\
\hline Enthalpy at the end of the LP turbine stage & 2559.9 & $\mathrm{~kJ} / \mathrm{kg}$ \\
\hline Mass flow rate at the end of the LP turbine stage & 64.8 & $\mathrm{~kg} / \mathrm{s}$ \\
\hline Output enthalpy from the ORC evaporator & 428.6 & $\mathrm{~kJ} / \mathrm{kg}$ \\
\hline Heat transfer coefficient of the ORC evaporator & 8.3 & $\mathrm{~kW} / \mathrm{m}^{2}$ \\
\hline Heating area of the ORC evaporator & 1000 & $\mathrm{~m}^{2}$ \\
\hline
\end{tabular}

The HP part of the BPT has been modeled by the parameters of the first arc, the second arc and end of the HP part. The HP partial arcs have been used for HP regenerative reheating.

The third arc has been placed between the HP and the LP parts. The steam from the arc has been used for technological steam and for pressure balance in feed water tank.

The rest of the steam from the HP part has been led to LP part of the BPT. The LP part has been modeled by the parameters from the fourth arc, the fifth arc and end of the LP part.

The last defined parameter is the enthalpy at the ORC evaporator (OE) output, which corresponds with the real enthalpy in the basic heater output under nominal operation. The OE construction parameters had to be determined for meeting sufficient heat transfer. These parameters are the heat transfer coefficient and transfer area.

The BPT model with the OE is shown in Figure 10. The mass flow rate of R-600a has been calculated as $420 \mathrm{~kg} / \mathrm{s}$ for the set of OE construction parameters in Table 1 . The mass flow rate of R-600a (i.e., $420 \mathrm{~kg} / \mathrm{s}$ ) has been sufficient for liquefaction of the wet steam (i.e., $64.7 \mathrm{~kg} / \mathrm{s}$ ) at the end of the LP part. The transferred heat power through the OE to the ORC has been estimated at $137.8 \mathrm{MWt}$.

The OT model, which is shown in Figure 11, is described further. All chosen ORC parameters are shown in Table 2. The expansion in the OT has been transformed into mechanical power on the shaft, which has been connected with the generator. The OT has been chosen as a one stage turbine. 


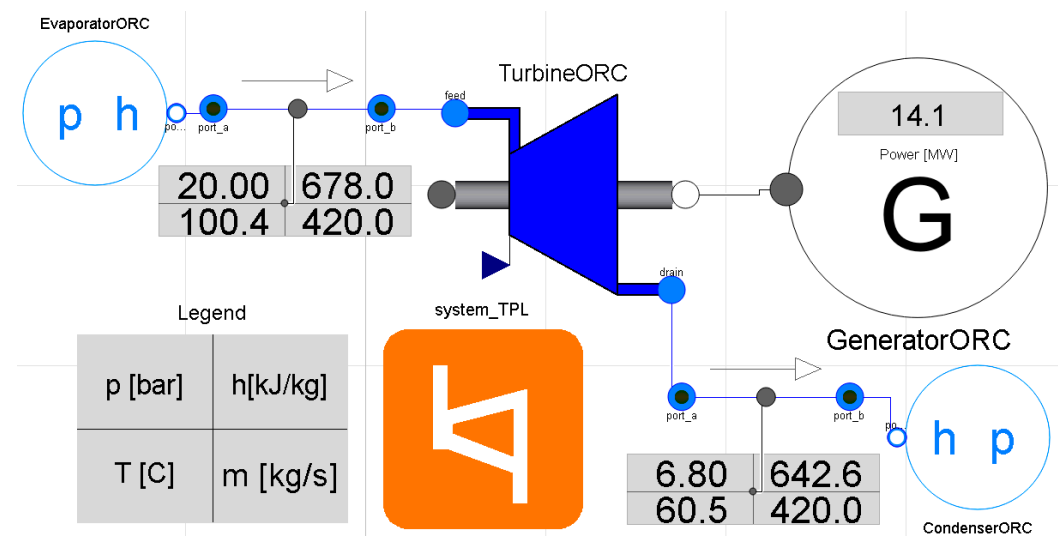

Figure 11. The model of one stage ORC turbine with working medium R-600a.

Table 2. Nominal thermodynamic parameters of the model of the ORC.

\begin{tabular}{ccc}
\hline Thermodynamic Parameters & Value & Unit \\
\hline Working medium & $\mathrm{R}-600 \mathrm{a}$ & - \\
Nominal thermal power & 137.8 & $\mathrm{MWt}$ \\
Nominal mass flow rate & 420 & $\mathrm{~kg} / \mathrm{s}$ \\
ORC turbine input temperature & 100.4 & ${ }^{\circ} \mathrm{C}$ \\
ORC turbine input pressure & 20 & $\mathrm{bar}$ \\
ORC turbine input enthalpy & 678 & $\mathrm{~kJ} / \mathrm{kg}$ \\
ORC turbine mechanical efficiency & 96 & $\% \%$ \\
ORC turbine isentropic efficiency & 85 & $\%$ \\
ORC turbine Baumann coefficient & 1 & - \\
ORC turbine output temperature & 60.5 & ${ }^{\circ} \mathrm{C}$ \\
ORC turbine output pressure & 6.8 & $\mathrm{bar}$ \\
ORC condenser heat transfer coefficient & 8.3 & $\mathrm{~kW} / \mathrm{m}^{2}$ \\
ORC condenser heating area & 1000 & $\mathrm{~m}{ }^{2}$ \\
ORC feed pump mechanical efficiency & 75 & $\%$ \\
Condenser feed pump mechanical efficiency & 75 & $\% \%$ \\
\hline
\end{tabular}

The main result of the OT model has been the calculation of its electric power. The nominal OT electric power has reached $14.1 \mathrm{MWe}$, which is shown in Figure 11 as well. The positive slope of the $\mathrm{R}-600 \mathrm{a}$ in the T-s diagram has been neglected for simplification. Therefore, a recuperative heater has not been considered in our modeling and the ORC condenser (OC) has been placed directly at the OT output.

The next modeled component has been the OC for liquefying the total amount of R-600a. The OC model is shown in Figure 12. The OC has been realized with the static heat exchanger model of using the logarithmic mean temperature difference. The main results of the OC model are transferred heat power $122.9 \mathrm{MWt}$ and mass flow rate of the cooling water $799.8 \mathrm{~kg} / \mathrm{s}$ for liquefying the R-600a.

The next modeled components have been the two feed pumps. These two feed pumps have created the most of own consumption. The first modeled feed pump (OFP) has been placed between the OC and the OE. The OFP model is shown in Figure 13. The R-600a pressure has been increased by 13.2 bars by the OFP. This is connected to a temperature increase by $10.8^{\circ} \mathrm{C}$ as well. The main result of the OFP model has been its electrical consumption. The OFP electrical consumption has been calculated as 5.037 MWe at mass flow rate $420 \mathrm{~kg} / \mathrm{s}$ of the R-600a. The OFP has had the most significant impact on the own consumption, because feed pumps for organic compounds must be much more robust and stronger than feed pumps for water, which would be 0.715 MWe (i.e., seven times less than for R-600a). 


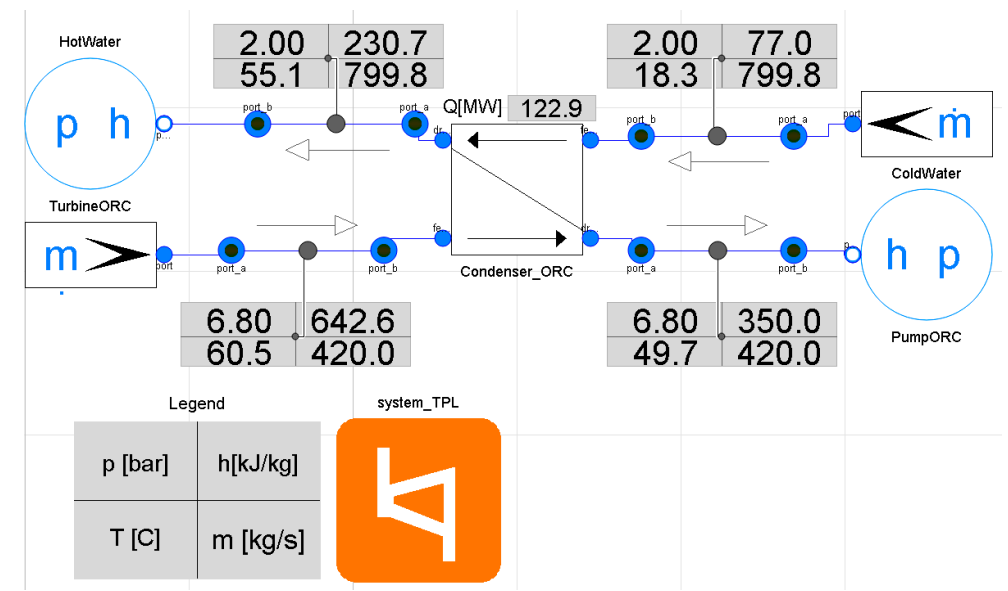

Figure 12. The model of the ORC condenser with R-600a working medium.

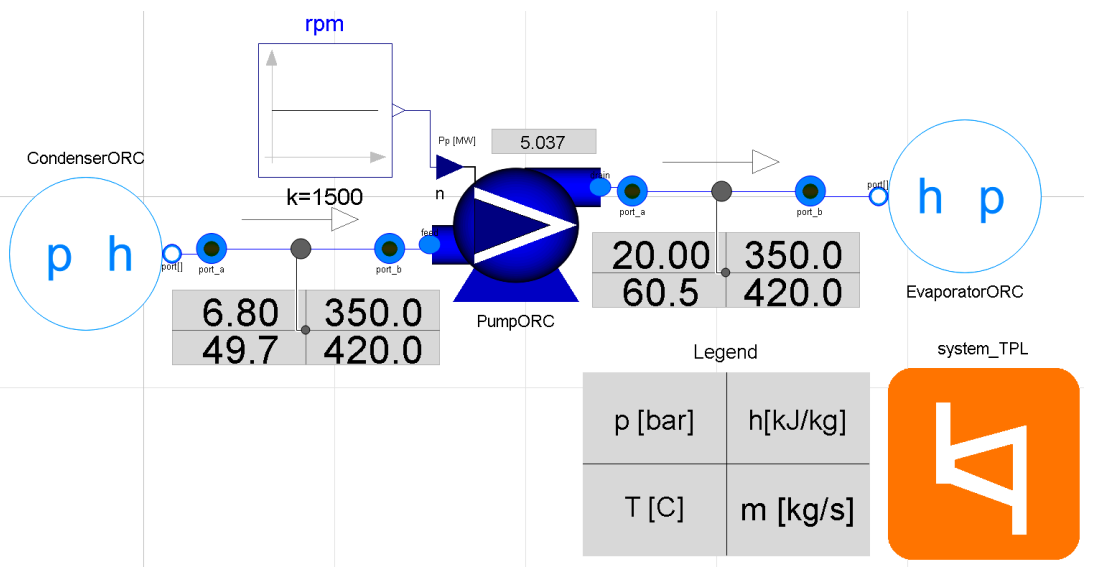

Figure 13. The model of the ORC feed pump with working medium R-600a.

The second modeled feed pump (CFP) has been placed on the OC primary side for cooling water feeding. The CFP model is shown in Figure 14. The cooling water pressure has been increased by 1 bar. The CFP electrical consumption has been calculated as 0.1 MWe at a cooling water mass flow rate of $799.8 \mathrm{~kg} / \mathrm{s}$. Although, the CFP impact has been smaller than the OFP, the CFP has not been neglected in further calculations.

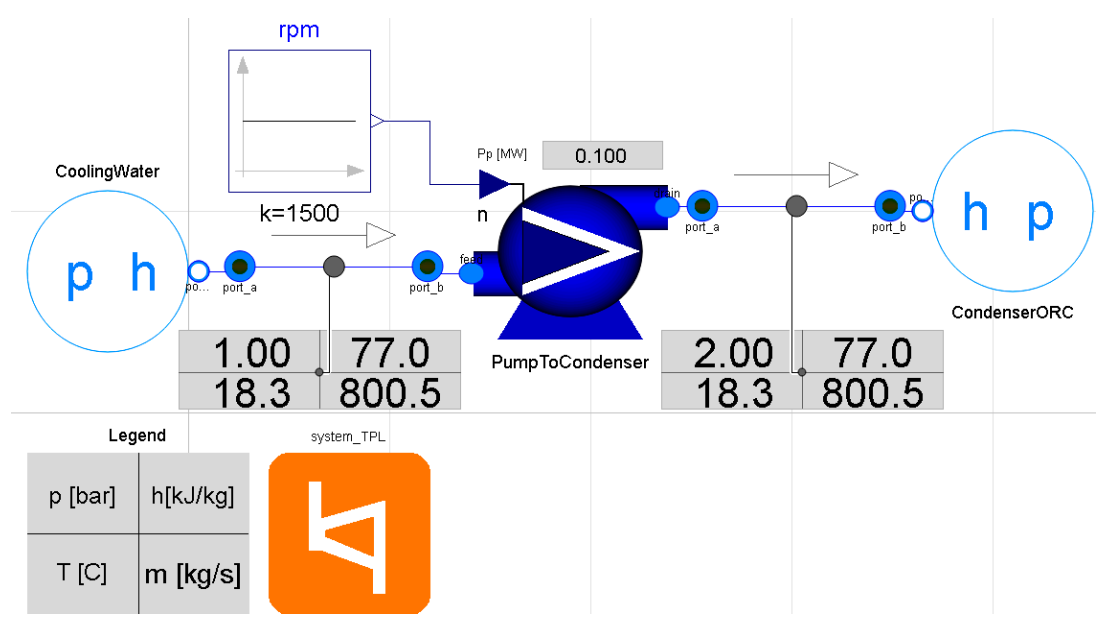

Figure 14. The model of the condenser feed pump with working medium R-600a. 


\section{Results}

Electric efficiency of the original BPT generally reaches around 30\% at the optimal conditions. The optimal conditions are tightly connected with the sufficient heat demand from the customer side. The heat demand can be very changeable and is strongly dependent on the ambient temperature. However, if the ORC will be implemented into the original BPT, it can solve the typical BPT problems.

All presented models have proven that the basic idea with the ORC implementation in the BPT cycle is possible and appropriate. The ORC has been designed with sufficient cooling power for liquefying steam (i.e., $137.8 \mathrm{MWt}$ ) in the original BPT cycle. For liquefying $64.7 \mathrm{~kg} / \mathrm{s}$ of the steam around $420 \mathrm{~kg} / \mathrm{s}$ of R-600a is needed at the given construction parameters of the EO, i.e., a heat transfer coefficient of $8.3 \mathrm{~kW} / \mathrm{m}^{2}$ and heating area of $1000 \mathrm{~m}^{2}$.

The electric production of the OT has been 14.1 MWe at a mass flow rate of $420 \mathrm{~kg} / \mathrm{s}$ of R-600a, input pressure 20 bars, input temperature $100.4{ }^{\circ} \mathrm{C}$, mechanical efficiency $96 \%$, isentropic efficiency $85 \%$ and Baumann coefficient for the OT equals 1.

The OC has a cooling power $122.9 \mathrm{MWt}$ and $799.8 \mathrm{~kg} / \mathrm{s}$ of cooling water is needed for liquefying $420 \mathrm{~kg} / \mathrm{s}$ of R-600a at the given construction parameters of the OC, i.e., $8.3 \mathrm{~kW} / \mathrm{m}^{2}$ and $1000 \mathrm{~m}^{2}$.

The OFP consumes 5.037 MWe of electric power. The pressure in the ORC has been increased by 13.2 bars and the temperature by $10.8^{\circ} \mathrm{C}$ by the OFP. The CFP has consumed $0.1 \mathrm{MWe}$ of electrical power. The pressure in the cooling circuit has been increased by 1 bar in the CFP. The CFP has led the cooling water to the OC.

The obtained electric power has been determined as the OT electric power (i.e., 14.1 MWe) minus the consumption of the ORC itself. The consumption includes both feed pumps' consumption and additional electric consumption, which has been connected with the cycle operation. The additional consumption has been estimated as roughly $0.2 \mathrm{MWe}$. Then, the total cycle self-consumption has been calculated:

$$
P_{\text {Tot.con. }}=P_{\text {ORCp. }}+P_{\text {Cond.p. }}+P_{\text {Add. }}=5.037+0.1+0.2=5.337 \mathrm{MWe} .
$$

The total self-consumption has been determined as 5.337 MWe. Then, the net ORC electric power has been calculated:

$$
P_{\text {Tot.obt. }}=P_{\text {ORCturbine }}-P_{\text {Tot.con. }}=14.1-5.337=8.763 \text { MWe. }
$$

The net electric power has been determined 8.763 MWe at the full ORC utilization. Then, the ORC efficiency has been calculated:

$$
\eta_{\text {ORC }}=\frac{P_{\text {Tot.obt. }}}{P_{\text {Trans.PC }}}=\frac{8.763}{233.4}=3.755 \%
$$

where $P_{\text {Trans.PC }}$ represents the total thermal power to the original BPT cycle.

The total thermal power of the original BPT cycle has been calculated as $233.4 \mathrm{MWt}$. The ORC efficiency has been calculated $3.755 \%$. The electric efficiency of the both cycles simultaneously will be estimated $33.755 \%$. This value of the efficiency is very similar to that of CTs.

However, the ORC efficiency will drop during partial operation. The sensitivity analysis of the ORC efficiency at the partial operation is shown in Figure 15. The ORC efficiency trend corresponds with the typical trend of overpressure turbines [11]. However, the ORC efficiency trend assumes the total thermal energy from the BPT will be led into the ORC, i.e., no heat demand.

The BPT improvement by the ORC implementation is shown in Figure 16. The trends in Figure 16 show the BPT electric efficiency with the ORC (orange curve) and without the ORC (blue curve).

Of course, Figures 15 and 16 represent the pure condensing operation. This is the state where the ORC offers the full utilization of the thermal energy from the BPT for generating electric power. 


\section{Total electric efficiency of the ORC}

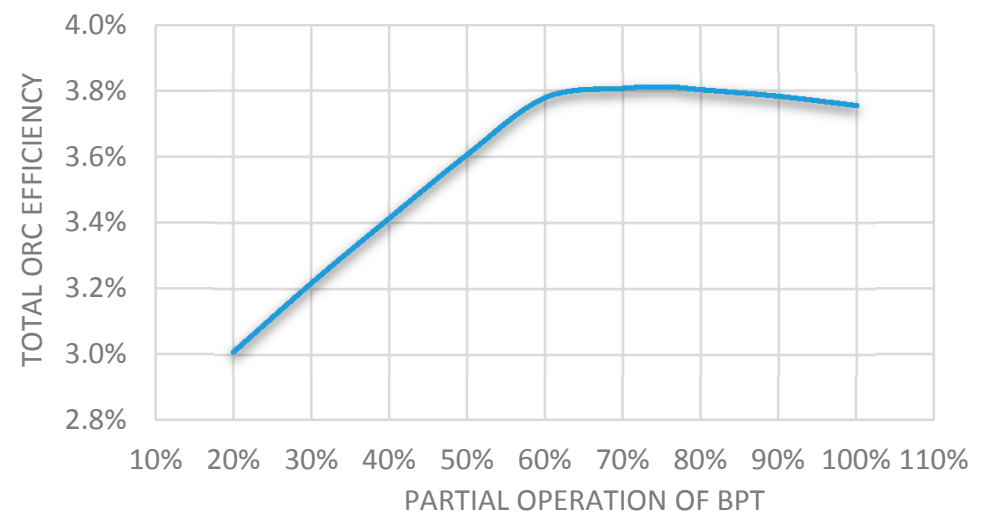

Figure 15. Sensitivity analysis of the ORC electric efficiency at the partial operation.

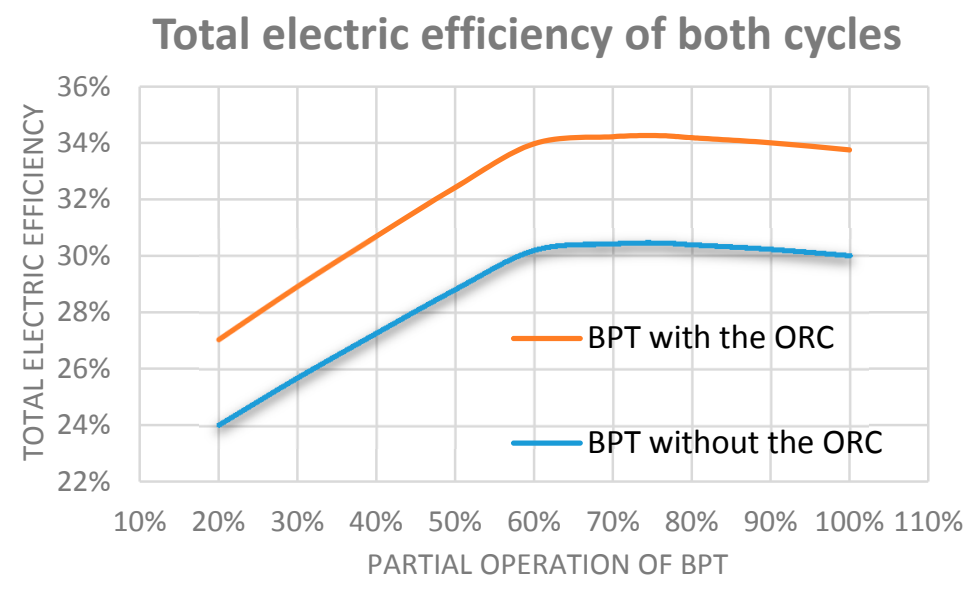

Figure 16. Sensitivity analysis of the BPT electric efficiency for two cases with and without the ORC.

The ORC can be used in cases with a lack of heat demand during a year as well. A certain part of the thermal energy can be utilized for district heating and the rest of the thermal energy can be utilized in the ORC. However, the ORC efficiency in that case will be lower. The drop of ORC efficiency will correspond with amount of utilized thermal energy in the ORC. The implementation of the ORC into BPT allows more flexible operation and additional electric production as well. Range of the ORC efficiency will be a little bit low. However, the ORC efficiency can be considered as the net improvement of the BPT electric efficiency, because there is not added any primary energy.

A technical-economic analysis has also been performed. The analysis has solved an economic return of the ORC implementation as well. However, there have been several basic assumptions, which had to be respected such as [13]:

- The assumed investment cost of the ORC has been considered as $5500 € / \mathrm{MWt}$ of a heat source.

- The assumed operation \& maintenance cost of the ORC has been considered as $2.4 € / \mathrm{MWh}$.

- The assumed price of electric energy has been considered as $80 € / \mathrm{MWh}$.

- The assumed thermal power of the heat source has been considered as $137.8 \mathrm{MWt}$.

Firstly, the total investment cost has been determined. The investment cost of the ORC implementation has been approximately:

$$
\text { Investment cost of the ORC }=5500 \times 137.8=757,900 € .
$$

After that, the average electric energies produced by the ORC per month in the summer and winter season, have been determined. The summer season has been considered as three typical summer 
months (June, July and August). The average electric power in the summer season has been calculated by analysis of the original BPT cycle from previous three years. An important assumption has been the ORC has been utilized at $90 \%$ of the nominal operation in the whole summer season:

Average electric energy of the ORC per month in the summer season $=644 \mathrm{MWh}$.

The winter season has been considered as the rest of a year (i.e., nine months). The average electric power in the winter season has been also calculated by analysis of the BPT cycle from three previous years. An important assumption has been the ORC has been utilized at $5 \%$ of the nominal operation in the whole winter season:

Average electric energy of the ORC per month in the winter season $=114 \mathrm{MWh}$.

The obtained average electric energies has been used for the calculation of the average electric power produced by the ORC per year:

Average electric energy of the ORC per year $=644 \times 3+114 \times 9=2958 M W h$.

The ORC income per year has been calculated. Of course, the income has assumed the modeled case, which has been mentioned above:

$$
\text { Income of the ORC per year }=2958 \times 80=236640 € \text { per year. }
$$

Operation \& maintenance cost of the ORC per year has been estimated:

$$
\text { O\&M cost of the ORC }=2958 \times 2.4=7099 € \text { per year. }
$$

The O\&M cost had to be subtracted from the income:

Net income of the ORC per year $=236640-7099=229451 €$ per year.

Finally, the investment return has been calculated:

$$
\text { Investment return of the } \mathrm{ORC}=757,900 / 311,952=3.3 \text { year. }
$$

The investment return looks promising for the already mentioned assumptions.

\section{Discussion}

All thermodynamic parameters for models have been based on real data under nominal operation conditions. The models have been created for better description of the improvement achieved by the ORC. Therefore, these models can be improved, optimized or extended in further investigation.

All reached results have proven the ORC with R-600a as the working medium could be used for this type of application. However, the state of the art has shown there are another two options, which could be also used for the solution of the typical BPT problems with a lack of heat demand. These two suitable options are:

- utilization of TES,

- utilization of absorption chillers.

There are several possible syntheses of various options as well:

- Only ORC

- ORC + TES

- ORC + absorption chillers 
- $\quad$ ORC + TES + absorption chillers

This paper is focused on using only the ORC into the BPT. However, there are more interesting options to deal with the problem. The already mentioned syntheses of options will be investigated in depth in our further investigations. However, other aspects of this problem must be taken into account such as the suitability of organic compounds for the application, optimization of all parts of the ORC, developing measurement and control systems for the ORC, etc.

It is important to mention what the impacts of the ORC implementation on the original BPT cycle can be. The ORC implementation will require only small changes in the original cycle (i.e., drilling of the last BPT output and adding one more valve). In the case of proper installation, the ORC implementation has a negligible impact on the original cycle. Only one valve will be added, which can theoretically cause a fault. However, this case can be solved by adding a redundant path to the basic heater.

\section{Conclusions}

The paper has introduced one possibility to utilize the ORC by insertion into the original BPT cycle. The insertion will solve two main disadvantages of the BPT. The first one is the poor flexibility of the BPT. The second one is that the BPT is strongly dependent on heat demand.

As it has been already shown, the electrical efficiency of the BPT is strongly dependent on heat demand at the last output of the BPT. This problem can be removed by the ORC, especially in times with a lack of heat demand.

The huge advantage can be the BPT can be operated at its nominal power even in the summer season, when a lack of heat demand often occurs. Moreover, the additional electric power, which can be produced by the ORC (i.e., up to $8.763 \mathrm{MWe}$ ), can improve the electric power possibilities of the whole power plant. Therefore, the power plant can more properly participate in the daily market with electrical power. It is also connected with a better price for the produced electrical energy.

The ORC components will have to be chosen and assessed in future investigations of the ORC reliability. The reliability of the ORC components will have to be optimized for the best possible sustainability of the ORC. However, the ORC implementation will have negligible impact on the original cycle [14].

The main conclusions of the paper can be summarized in the following points:

- The original BPT in the Pilsen CPP has produced at the nominal production 70 MWe and $137.8 \mathrm{MWt}$, bad operation flexibility and the problem under lack of heat demand conditions.

- Solution of the BPT problems can be possible by the ORC implementation. The ORC implementation can increase the operational flexibility of the BPT and can fix the problem of a lack of heat demand.

- One of the ORC implementations has been modeled by thermodynamic models. The working medium has been chosen as R-600a and the ORC has been calculated to cover exactly the same heat energy as the basic heater at the last output of the original BPT.

- The additional electric power, which has been produced by the ORC, has been calculated at 14.1 MWe.

- The consumption of the ORC has been determined as 5.337 MWe.

- From previous values, the net electric power 8.763 MWe has been calculated at the full ORC utilization. This corresponded with an ORC efficiency of 3.755\% and with an added electric efficiency of both cycles of $33.755 \%$.

- The calculated total efficiency is comparable with the CT efficiency.

- The investment return has been estimated at 3.3 years; this value is dependent on the ORC utilization. 
Author Contributions: Conceptualization: A.H.; Methodology: A.H. and M.S.; Software: A.H.; Validation: A.H., M.S. and Z.M.; Formal Analysis: A.H., M.S. and Z.M.; Investigation: A.H. and M.S.; Resources: A.H., M.S. and Z.M.; Writing-Original Draft Preparation: A.H.; Writing-Review \& Editing: A.H., M.S. and Z.M.; Visualization: A.H.; Supervision: M.S. and Z.M.; Project Administration: M.S.; Funding Acquisition: M.S. and Z.M.

Funding: This paper is supported by the student research project SGS-2018-023 and the program for support of applied research and experimental development Centre of Advanced Nuclear Technologies (CANUT) TH02020798.

Conflicts of Interest: The authors declare no conflict of interest.

\section{References}

1. Luo, X.; Wang, J.; Dooner, M.; Clarke, J. Overview of current development in electrical energy storage technologies and the application potential in power system operation. Appl. Energy 2015, 137, 511-536. [CrossRef]

2. Letcher, T.M. Storing energy: With special reference to renewable energy sources. Chem. Int. 2016, 38, 28-29.

3. Farhad, M.H.; Malek, A.A.; Hasanuzzman, M.; Rahim, N.A. Technical Review on Biomass Conversion Processes into Required Energy Form. In Proceedings of the 2013 IEEE Conference on Clean Energy and Technology (CEAT), Lankgkawi, Malaysia, 18-20 November 2013; pp. 208-213.

4. Hromádka, A. Kombinovaná výroba tepla a elektřiny v Plzeňské teplárenské a.s. Available online: http: //hdl.handle.net/11025/7252 (accessed on 25 May 2019).

5. Zuwała, J. Life cycle approach for energy and environmental analysis of biomass and coal co-firing in CHP plant with backpressure turbine. J. Clean. Prod. 2012, 35, 164-175. [CrossRef]

6. Hromádka, A.; Martínek, Z. Overview of the organic Rankine cycles and their current utilization: Verification of several current ORCs utilization by the software Dymola. In Proceedings of the 18th International Scientific Conference on Electric Power Engineering (EPE), Kouty nad Desnou, Czech Republic, 17-19 May 2017; pp. 1-6.

7. Shengjun, Z.; Huaixin, W.; Tao, G. Performance comparison and parametric optimization of subcritical Organic Rankine Cycle (ORC) and transcritical power cycle system for low-temperature geothermal power generation. Appl. Energy 2011, 88, 2740-2754. [CrossRef]

8. Mago, P.; Louay, J.; Chamra, M.; Srinivasan, K.; Somayaji, C.h. An examination of regenerative organic Rankine cycles using dry fluids. Appl. Therm. Eng. 2008, 28, 998-1007. [CrossRef]

9. Saleh, B.; Koglbauer, G.; Wendland, M.; Fischer, J. Working fluids for low-temperature organic Rankine cycles. Energy 2007, 32, 1210-1221. [CrossRef]

10. Wu, C.H.; Wang, S.; Bai, K.; Li, J. Thermodynamic analysis and parametric optimization of CDTPC-ARC based on cascade use of waste heat of heavy-duty internal combustion engines (ICEs). Appl. Therm. Eng. 2016, 106, 661-673. [CrossRef]

11. Hromádka, A.; Martínek, Z.; Sirový, M.; Jiřičková, J. Comprehensive mathematical model of the turbomachinery in the czech nuclear power plant Temelin: Verification of the Thermal power library model for the Dymola software by real measurement data from the power plant. In Proceedings of the 9th International Scientific Symposium on Electrical Power Engineering (ELEKTROENERGETIKA), Košice, Slovakia, 12-14 September 2017; pp. 545-550.

12. Cooke, D.H. On Prediction of Off-Design Multistage Turbine Pressures by Stodola's Ellipse. J. Eng. Gas Turbines Power 1985, 107, 596-606. [CrossRef]

13. Herzog, U. Technical and Economical Experiences with Large ORC Systems Using Industrial Waste Heat Streams of Cement Plants. Available online: https://docplayer.net/62212086-Technical-and-economicalexperiences-with-large-orc-systems-using-industrial-waste-heat-streams-of-cement-plants.html (accessed on 4 July 2019).

14. Martinek, Z.; Hromadka, A.; Hammerbauer, J. Reliability Characteristics of Power Plants. Adv. Electr. Electron. Eng. 2017, 15, 37-45. [CrossRef]

(C) 2019 by the authors. Licensee MDPI, Basel, Switzerland. This article is an open access article distributed under the terms and conditions of the Creative Commons Attribution (CC BY) license (http://creativecommons.org/licenses/by/4.0/). 